\title{
The Development of Distributive Justice: Does Type of Schooling really matter?
}

\author{
Dr. Rita Karmakar*, Prof. Anjali Ghosh**
}

\begin{abstract}
Distributive justice is the normative principle designed to guide the allocation of resources among the members of a community. Distributive justice in the context of reward allocation mainly deals with various determinants of preference for specific justice (allocation) rules, such as equity (merit), equality, need and seniority (Deutsch, 1985; Homans, 1961; Leventhal, 1980). The present study has been undertaken to determine the role of age, gender and type of schooling on the development of distributive justice of children. Participants of the study were 200 children $(100$ from missionary and 100 from non-missionary schools) belonging to Kolkata district, West Bengal. The results indicated the role of type of schooling and age on the development of distributive justice of adolescents. Pre adolescents generally prefer equality as justice criteria whereas adolescents generally prefer merit as their justice criteria. Effect of type of schooling is prominent among pre-adolescents.
\end{abstract}

KEY WORDS: Distributive Justice, Preadolescents, adolescents, Missionary and Nonmissionary schools.

\footnotetext{
* Indian Institute of Management (IIM), Calcutta

** Indian Statistical Institute, Calcutta
} 


\section{INTRODUCTION}

Distributive justice relates to the perceived fairness of reward allocation. It plays a critical role in guiding individuals' behavior, regulating social interactions and maintaining the structure and functions of society as a whole. The following four allocation rules are most common in the field of distributive justice research (Deutsch, 1985). Equity rule - rewards are distributed proportionally to individual contributions; equality rule - everyone's reward is identical regardless of individual contributions; seniority rule - outcomes are distributed proportionally to seniority (age) and need rule - outcomes are distributed proportionally to individual needs.

A bulk of researches has shown that the development justice concept depends on age. Studies on age and distributive justice have reported developmental trends suggested by developmental theorists. These studies have reported that younger children (under 6 years of age) generally follow either self-interest or strict equality, children (approximately 6-12 years) adopt an "ordinal equity" approach and children (13 years onwards) follow "proportional equity" approach (Leventhal \& Anderson, 1970; Lane \& Coon, 1972; Hook \& Cook, 1979) at the time of resource allocation. Some studies have shown the departures from the trends as suggested by developmental theorists. These studies have indicated that preschool and kindergarten children prefer equality and sometimes follow equity norm when appropriate instructions are given (Leventhal, Popp \& Sawyer, 1973; Lerner, 1974; Nelson \& Dweck, 1977). Studies conducted in Indian context on school students have shown a preference for equality over need and equity by Indian subjects (Sinha, Hassan, Carment \& Krishnan, 1986; Krishnan, 1987). Another study in Indian context has revealed that children (approximately 9-12 years) generally follow equality and children (approximately 13-15 years) adopt merit as a justice rule (Ghosh \& Karmakar, 2005). Studies examining the role of gender on the pattern of distributive justice have revealed that generally girls prefer equality while boys prefer equity (Benton, 1971; Kahn, O'Leary, Krulewitz, \& Lamm, 1980; Major \& Deaux, 1982). Except these demographic variables, the development of distributive justice is assumed to be influenced by school atmosphere and pattern of teaching in schools. In missionary 
schools, there is a provision for moral teaching whereas in the non-missionary schools there is no such teaching given to children, but little is known about the impact of school experiences on distributive justice development.

\section{AIMS OF THE STUDY}

The present study aims to find out -

(a) To study the role of age in the formation of distributive justice of children. For this purpose, preadolescents and adolescents have been selected in the present study.

(b) To study the role of gender in the formation of distributive justice of children. For this purpose, boys and girls have been selected in the present study.

(c) To study the role of type of schooling in the formation of distributive justice of children. For this purpose, children studying in missionary and non missionary schools have been selected in the present study.

\section{METHODOLOGY}

\section{Sample:}

Participants of this cross-sectional study were 200 school children (100 from missionary and 100 from non-missionary) belonging to Kolkata districts of West Bengal. Boys and girls were kept equal in the sample and their age range varied from 10-16 years with a mean age of 13.07 years $(\mathrm{SD}=2.87)$. Students below the mean age were considered as pre adolescents and at or above mean were considered as adolescents. A stratified random sampling method was used for the selection of type of schooling (missionary and non-missionary) for the study. A random sampling method was used for selecting schools from each stratum (missionary and nonmissionary). Six schools (three from each stratum) were taken as sample for the present study. From selected schools, students of two different age groups were selected by using simple random sampling without replacement (SRSWOR). The students were from middle socio economic status. 


\section{Tools used:}

The following tools were used in this study:

Personal Data sheet: Certain personal information about respondents included in the sample of research is useful and important for research. Here also, for collecting such important information, personal data sheet was prepared. With the help of this personal data sheet, the information about age, gender, type of schooling and total monthly income of family were collected.

\section{Distributive Justice Scale (DJS):}

For assessing distributive justice of the children, Distributive Justice Scale (DJS) of Enright, Franklin and Manheim (1980) was administered. This scale is based on Damon's theory $(1980,1981)$ of distributive justice. According to Damon $(1980,1981)$, the development of distributive justice follows a six stage of progression. At Level 0-A, self-interest is the governing distributive criteria; at Level 0-B, self-interest is backed up with an appeal to external, physical and observed features, such as size, age and gender. At Level 1-A , notion of strict equality governs sharing and the ideas of merit, deserving and reciprocity emerge at Level 1-B. At Level 2-A, one attempts to balance between competing claims to merit by working out some equitable compromises and special circumstances such as recipient's need, etc., while judging fairness. At the highest level, i.e. Level 2-B, the compromise between equity (merit) and reciprocity is worked out in the light of the demands of the situation or the larger goals and purposes of the group.

The DJS is a standardized and objectively scored paired-comparison test. Each participant is presented with 15 social dilemmas. For each dilemma, there are two alternative choices, given by means of two pictures accompanied by statements, representing two different stages of DJS to be compared. These 15 dilemmas cover all the $\left(\begin{array}{l}6 \\ 2\end{array}\right)=15$ possible paired comparisons. For each dilemma (or pair of pictures with statements), the participant is asked which picture better ends the story. The order of 
presentation of the dilemma is randomized, and within each dilemma, the decision as to which one would be presented first is also randomized to control the order effects. Three dilemmas are repeated to check for consistency. The repeated pairs are presented in reverse order of their original pairings to control for primacy or recency effects. The dominant stage chosen by a participant in all these 15 dilemmas gives the observed DJS for the participant. In case of tie with two stages, the one chosen while comparing these two particular stages is the DJS score. A similar mechanism is there to break a tie involving more than two stages. These six stages are denoted by Stage 0 , Stage 0.5 , Stage 1, Stage 1.5, Stage 2 and Stage 2.5. The numbers have nothing to do with the magnitude of the stages except the ordering between them. These six stages are similar to Damon's six levels of distributive justice as described above. Some minor modifications with the permission of the author have been made in the scale to suit the Indian context. The test retest reliability coefficient is 0.76 and internal consistency coefficient is 0.73 .

\section{Statistical Analyses:}

In this study, Independent ' $t$ ' test and three way (2X2X2) Analysis of Variance (ANOVA) were used for statistical analysis.

\section{RESULT AND DISCUSSION}

The data collected from boys and girls of missionary and non-missionary school were first scored and then different analyses were carried out to see the impact of different variables. The results are presented in the following sections:

\section{Distributive justice by type of schooling}

Means, standard deviations (SDs) and independent $t$ tests were calculated in order to find out whether the children of missionary and non-missionary schools differ significantly with respect to their distributive justice and the result is presented in Table 1. 
Table 1: Means, Standard Deviations (SD) and t-value of distributive justice of children studying in missionary and non-missionary schools

\begin{tabular}{|l|l|l|l|}
\hline Age Group & Mean & SD & t-value \\
\hline Missionary (N=100) & 2.05 & 1.02 & $3.32^{* *}$ \\
\cline { 1 - 2 } Non-Missionary $(\mathrm{N}=100)$ & 1.58 & 0.98 & \\
\hline
\end{tabular}

Note. ** Significant at 0.01 level.

Table 1 indicates that children of missionary schools are significantly higher on distributive justice than their non-missionary counterparts. This result indicates the potential impact of the school context on distributive justice. Children of missionary schools tend to choose need (Stage 2) over any other principles of distributive justice whereas merit (Stage 1.5) is being preferred by children of non-missionary schools.

\section{Distributive justice by age}

Data were also collected from different age group of children. To determine whether pre adolescents and adolescents differ significantly with respect to distributive justice means, standard deviations (SDs) and independent t test were calculated and the result is presented in the following table:

Table-2: Means, Standard Deviations (SD) and t-value of distributive justice preadolescents and adolescents.

\begin{tabular}{|l|l|l|l|}
\hline Group & Mean & SD & t -value \\
\cline { 1 - 3 } Pre-adolescent $(\mathrm{N}=110)$ & 1.18 & 0.50 & $4.72 * *$ \\
\cline { 1 - 3 } Adolescents $(\mathrm{N}=90)$ & 1.61 & 0.78 & \\
\hline
\end{tabular}

Note. ** Significant at 0.01 level.

It is revealed in Table 2 that mean score of distributive justice of pre-adolescents differ significantly from adolescents. Pre-adolescents tend to prefer equality (Stage 1) whereas merit (Stage 1.5) is being preferred by adolescents. 


\section{Distributive justice by gender}

To determine whether boys and girls differ significantly with respect to distributive justice means, standard deviations (SDs) and independent $t$ test were calculated and the result is presented in Table 3.

Table-3: Means, Standard Deviations (SD) and t-value of distributive justice boys and girls

\begin{tabular}{|l|l|l|l|}
\hline Group & Mean & SD & t -value \\
\cline { 1 - 3 } Boys (N=100) & 1.48 & 0.70 & 1.43 \\
\cline { 1 - 3 } Girls (N=100) & 1.61 & 0.58 & \\
\cline { 1 - 2 } & &
\end{tabular}

It is revealed from above table that the mean distributive justice of girls is slightly greater than boys. The mean difference of distributive justice scores between boys and girls is not statistically significant.

To determine the interaction effect of type of schooling, age and gender on distributive justice, three-way ANOVA $(2 \times 2 \times 2)$ was carried out and the results are presented in the following table:

Table 4: 2 X 2 X 2 ANOVA of distributive justice.

\begin{tabular}{|l|l|l|l|l|}
\hline Source variable & df & Sum of squares (SS) & Mean SS & F ratio \\
\hline Type of school (A) & 1 & 10.50 & 10.50 & $23.86^{* *}$ \\
\hline Age (B) & 1 & 7.58 & 7.58 & $17.23^{* *}$ \\
\hline Gender (C) & 1 & 0.78 & 0.78 & 1.77 \\
\hline A X B & 1 & 7.78 & 7.78 & $17.68^{* *}$ \\
\hline A X C & 1 & 1.07 & 1.07 & 2.43 \\
\hline B X C & 1 & 0.89 & 0.89 & 2.02 \\
\hline A X B X C & 1 & 1.87 & 1.17 & 2.65 \\
\hline Within group error & 192 & 83.95 & 0.44 & ----- \\
\hline
\end{tabular}

Note. ${ }^{* *}$ Significant at 0.01 level.

Table 4 indicates that type of schooling, age and interaction between these two variables play a crucial role in the development of distributive justice. It can be seen from 
Table 1 and 2 that children of missionary schools are significantly higher than their nonmissionary counterparts and adolescents are significantly higher on distributive justice than pre-adolescents. The closer scrutiny on the interaction effect reveals that type of schooling has significant effect only on pre-adolescents. Most of the pre-adolescents studying in missionary schools tend to choose equality (stage 1) whereas those studying in non-missionary schools are more likely to prefer self interest principle (Stage 0.5) of distributive justice. Adolescents of missionary and non-missionary schools do not differ significantly with respect to distributive justice. The probable reason for this is that understanding of justice concepts by pre-adolescents is directly linked to their everyday experiences and instructions given in the educational institutions.

\section{CONCLUSIONS}

From the findings of the present study the following conclusions may be drawn-

(1) The type of schooling (missionary and non-missionary) has significant impact on the development of distributive justice especially on preadolescents. The obtained result throws better light on the influence of knowledge on justice concepts and system of teaching in missionary and non-missionary schools. The study also reveals that preadolescents are more open to receive information given in schools whereas justice concepts are already being developed by the time one reaches adolescence.

(2) Preadolescents are more likely to prefer equality principle of justice in order to maintain interpersonal harmony whereas adolescents tend to prefer merit.

(3) Gender does not play any significant role in the development of distributive justice.

\section{LIMITATIONS OF THE STUDY}

- The sample was drawn from West Bengal state only hence it can be not generalised. 
- While selecting the sample religion (Hindu, Muslim etc), type of area (rural, urban and semi-urban), family type (joint, nuclear and extended) are not taken in to consideration, so religion, type of area and family type wise difference cannot be inferred from the data.

- Home environment also plays a crucial role in developing justice concepts. A study including this variable may give some other directions.

\section{IMPLICATION OF THE STUDY}

In spite of having all the limitations, the present study has some implications:

- The findings of the study explicitly bring about the pattern of distributive justice in pre-adolescents and adolescents. Factors such as age, type of schooling are some of the main governing sources in the formation of justice concepts. School atmosphere may contribute significantly towards building up the justice concepts especially among preadolescents because their concepts can easily be moulded by the instructions given in the schools.

- In every school there should be some provision for teaching values and justice concepts which ultimately facilitate the development of values, concern for others, sense of cooperation and moral character of children which in turn help to develop healthy personality and good citizen of country.

\section{REFERENCES}

1. Benton, A. A. (1971). Productivity, distributive justice, and bargaining among children. Journal of Personality and Social Psychology. 18, 68-78.

2. Damon, W. (1980). Patterns of change in children's social reasoning: A two-year longitudinal study. Child Development, 51, 1010-17.

3. Damon,W. (1981). The development of justice and self-interest during childhood. In M.J. Lerner, \& S.C. Lerner. (Eds.), The justice motive in social behavior (pp. 57-72). New York \& London: Plenum Press.

4. Deutsch, M. (1985). Distributive justice. New Haven, CT: Yale University Press.

5. Enright, R. D., Franklin, C. C., \& Manheim, L. A. (1980). Children's distributive justice reasoning: A standardized and objective scale. Developmental Psychology, $16,193-202$. 
6. Ghosh, A., and Karmakar, R. (2005). Distributive Justice and Parent- child Relationship in School Students. In A. Hussain, S. Hussain, and Md. H.R. Khan (Eds). Applied Indian Psychology: New Perspectives. 19-31, New Delhi, Global Vision Publishing House.

7. Homans, G.C. (1961). Social behavior: Its elementary forms. New York: Harcourt, Brace \& World.

8. Hook, J. G., \& Cook, T. D. (1979). Equity theory and the cognitive ability of children. Psychological Bulletin, 86(3), 429-445.

9. Kahn, A., O'Leary, V. E., Krulewitz, J. E., \& Lamm, H. (1980). Equity and equality: Male and female means to a just end. Basic and Applied Social Psychology, 1, 173-197.

10. Krishnan, L. (1987). Equality and equity in reward distribution in an Indian setting. Psychological Studies, 32(2), 97-103.

11. Lane, I. M., \& Coon, R. C. (1972). Reward allocation in preschool children. Child Development, 43, 1382-1389.

12. Lerner, M.J. (1974). The justice motive: "Equity" and "Parity" among children. Journal of Personality and Social Psychology, 29(4), 539-550.

13. Leventhal, G. S. (1980). What should be done with equity theory? In K. Gergen, M.Greenberg, \& R.Willis (Eds.), Social exchange theory (pp. 27-55). New York: Plenum Press.

14. Leventhal, G. S., Popp, A. L., \& Sawyer, L. (1973). Equity or equality in children's allocation of reward to other persons? Child Development, 44 (4), 753763.

15. Leventhal, G.S., \& Anderson, D. (1970). Self interest and the maintenance of equity. Journal of Personality and Social Psychology, 15, 57-62.

16. Major, B., \& Deaux, K. (1982). Individual differences in justice behavior. In J. L. Greenberg, \& R. L. Cohen (Eds.), Equity and justice in social behavior. New York: Academic Press.

17. Nelson, S. A., \& Dweck, C. S. (1977). Motivation and competence as determinants of young children's reward allocation. Developmental Psychology, 13(3), 192-197.

18. Sinha, J. B. P., Hassan, A., Carment, D. W., \& Krishnan, L. (1986). Allocatorrecipient closeness, nature of reward and resource allocation rule preference in India. Unpublished study. 